\title{
An operational system for the assimilation of the satellite information on wild-land fires for the needs of air quality modelling and forecasting
}

\author{
M. Sofiev ${ }^{1}$, R. Vankevich ${ }^{2}$, M. Lotjonen ${ }^{1}$, M. Prank ${ }^{1}$, V. Petukhov ${ }^{2}$, T. Ermakova ${ }^{2}$, J. Koskinen ${ }^{1}$, and J. Kukkonen ${ }^{1}$ \\ ${ }^{1}$ Finnish Meteorological Institute, Erik Palmenin aukio 1, P.O. Box 503, 00101, Helsinki, Finland \\ ${ }^{2}$ Russian State Hydrometeorological University, Malookhtinsky Avenue 98, 195196, St. Petersburg, Russia
}

Received: 14 November 2008 - Published in Atmos. Chem. Phys. Discuss.: 10 March 2009

Revised: 30 July 2009 - Accepted: 27 August 2009 - Published: 18 September 2009

\begin{abstract}
This paper investigates a potential of two remotely sensed wild-land fire characteristics: 4- $\mu \mathrm{m}$ Brightness Temperature Anomaly (TA) and Fire Radiative Power (FRP) for the needs of operational chemical transport modelling and short-term forecasting of atmospheric composition and air quality. The treatments of the TA and FRP data are presented and a methodology for evaluating the emission fluxes of primary aerosols $\left(\mathrm{PM}_{2.5}\right.$ and total $\left.\mathrm{PM}\right)$ is described. The method does not include the complicated analysis of vegetation state, fuel load, burning efficiency and related factors, which are uncertain but inevitably involved in approaches based on burnt-area scars or similar products. The core of the current methodology is based on the empirical emission factors that are used to convert the observed temperature anomalies and fire radiative powers into emission fluxes. These factors have been derived from the analysis of several fire episodes in Europe (28.4-5.5.2006, 15.8-25.8.2006 and in August 2008). These episodes were characterised by: (i) well-identified FRP and TA values, and (ii) available groundbased observations of aerosol concentrations, and optical thickness for the regions where the contribution of the fire smoke to the concentrations of $\mathrm{PM}_{2.5}$ was dominant, in comparison with those of other pollution sources. The emission factors were determined separately for the forested and grassland areas; in case of mixed-type land use, an intermediate scaling was assumed. Despite significant differences between the TA and FRP methodologies, an accurate nonlinear fitting was found between the predictions of these approaches. The agreement was comparatively weak only for small fires, for which the accuracy of both products is ex-
\end{abstract}

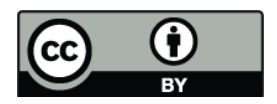

Correspondence to: M. Sofiev (mikhail.sofiev@fmi.fi) pected to be low. The applications of the Fire Assimilation System (FAS) in combination with the dispersion model SILAM showed that both the TA and FRP products are suitable for the evaluation of the emission fluxes from wild-land fires. The fire-originated concentrations of aerosols $\left(\mathrm{PM}_{2.5}\right.$, $\mathrm{PM}_{10}$, sulphates and nitrates) and AOD, as predicted by the SILAM model were mainly within a factor of 2-3 compared with the observations. The main challenges of the FAS improvement include refining of the emission factors globally, determination of the types of fires (smouldering vs flaming), evaluation of the injection heights of the plumes, and predicting the temporal evolution of fires.

\section{Introduction}

Each year about $5000 \mathrm{~km}^{2}$ of forested land in Europe is burned by more than 50000 fires (Keramitsoglou et al., 2004). The wild-land fires occur in all European countries being particularly intensive in the arid southern and eastern regions. Globally, vast forests of Russia and Brazil, as well as those in central Africa, are among the most severely affected areas. Total estimates of the consumed biomass vary widely, usually ranging between 5 and 10 Gtons annually (Scholes and Andreae, 2000; Chin et al., 2002).

The fires in different parts of the globe have specific regional characteristics. For instance, in forested regions, such as Siberia or Alaska, the main impact and the amount of consumed biomass can be attributed to a comparatively small number of major episodes. Conversely, in Africa and in arid regions a typical intensity of individual fires is smaller but their count is much larger (Schultz et al., 2008). In Europe, patchy land use and variety of climatic zones increase the

Published by Copernicus Publications on behalf of the European Geosciences Union. 
diversity. In northern areas, boreal-forest and bog fires are the most usual types of fires. In central Europe, grass and mixed-forest fires are more frequent, while in the south the fires of grassland and sub-tropical forests are the standard ones. The European fire season starts in April and can last until the end of November when seasonal precipitation has wetted the surface and vegetation in the Southern Europe. The impact of fires on climate processes, atmospheric composition and air quality also varies widely from region to region and its estimates may differ significantly between different studies (e.g. Barbosa et al., 1999; Wotawa et al., 2001; Schultz, 2002; Generoso et al., 2003; Duncan et al., 2003; Soja et al., 2004; van der Werf et al., 2004; Schultz et al., 2008).

Most of the fires are ignited by humans, either deliberately or accidentally. It is, therefore, difficult to make quantitative predictions regarding individual fire events. As a result, the forecasting capability of various fire indices is limited, although they can be successfully correlated with the probability of the ignited flames to develop into a full-scale fire (Tanskanen and Venäläinen, 2008).

Presently, a widely used methodology for obtaining the fire information for real-time applications is based on the operational in-situ and remote sensing observations of active fires - using fire monitoring towers, aircrafts or satellites. One of major European efforts is the European Forest Fire Information System EFFIS (http://effis.jrc.ec.europa.eu) maintained by the Joint Research Centre. Its database includes upto-date and historical information about the European fires from 20 European countries. EFFIS also incorporates the fire danger forecast and an outlook of the current fire situation, mainly based on remote-sensing fire detection (MODIS hot spot counts).

There are two main types of remote-sensing information that are suitable for assessing the features and impacts of fires: products based on estimating the burnt areas, and those using the derivatives of observations of surface temperatures, i.e., hot spot counts and fire radiative power (Flemming, 2005).

Most of the above-mentioned studies are based on the analyses of burnt areas, which are primarily performed on a monthly basis and diagnosed via, for example, albedo changes at specific wavelengths. Examples of the burnt area products are GLOBSCAR from the ATSR instruments ( $\mathrm{Si}$ mon et al., 2004) and Global Burnt Area 2000 (GBA2000) from SPOT-VEGETATION (Tansey et al., 2004). The burnt area estimates are uncertain and, according to Boschetti et al. (2004), the difference between GLOBSCAR and GBA2000 can be as large as a factor of two. There are no burnt-area products available in near-real-time (NRT) at present, which allows the utilization of this type of data only in re-analysis studies.

The other type of input data is based on surface temperature observations and their derivatives. Dozier (1981) and Matson and Dozier (1981) showed that using the information from $3.8 \mu \mathrm{m}$ and $11 \mu \mathrm{m}$ thermal infrared channels one can detect "sub-resolution scale high temperature sources, and to estimate both the temperature and size of such sources". This bi-spectral method exploits the different sensitivities of the channels to thermal emission. A sensitivity analysis of Giglio and Kendall (2001) has shown that in realistic conditions the random errors in fire temperature and area retrieved using Dozier's method are $\pm 100 \mathrm{~K}$ and $\pm 50 \%$ at one standard deviation, respectively, for fires occupying a pixel fraction greater than 0.005. The WF ABBA algorithm (Prins et al., 2001) builds on the algorithm by Dozier (1981) to retrieve wildfire size and temperature products from the GOES-8 geostationary meteorological satellite operationally in NRT.

The few intercomparison studies made so far for the burntarea and hot-spot count approaches indicate severe differences between the methods and even between the retrievals based on the same principle (Boschetti et al., 2004).

Most methods to convert the fire information to emissions of atmospheric tracers are based on empirical scaling coefficients from the burnt area (models GWEM of Hoelzemann et al. (2004), FLAMBE of Reid et al. (2004), INPE/CPTEC of Freitas et al., 2005) or, rarely, from the hot spots (GFED, Van der Werf et al., 2003) to fluxes of a mixture of species. The lists of species included in the emission models vary but usually $\mathrm{CO}_{2}, \mathrm{CO}$ and the total mass of aerosols are included, as these are amongst the most important constituents emitted by fires and measured in the atmosphere, thus allowing a direct calibration of a modelling system. More detailed chemical speciation is usually based on the review by Andrea and Merlet (2001, AM01), in which the most widely used emission factors are provided for the main land use types. However, the speciation also depends on the state of the vegetation, which resulted in a wide range of uncertainties of the mean emission factors.

One of the early operational Fire Alarm Systems based on hot-spot satellite information has been developed in Finland in the mid-1990's and is still operational (Kelhä et al., 2003). The system utilizes the products from the AVHRR and AATSR instruments and generates alarm messages for the authorities and fire-fighting services, if an overheated pixel (compared to the neighbouring ones) appears anywhere in Finland. However, the system provides only qualitative information (the appearance of a fire) and does not describe its intensity or the chemical composition of the emissions.

The goal of the current paper is to present a newgeneration Fire Assimilation System (FAS), which evaluates globally the emission fluxes of primary particulate matter originated from wild-land fires on a daily resolution. The predicted emissions in Europe are subsequently scaled to other pollutants using emission factors from the literature and submitted to the chemical transport model SILAM (http://silam.fmi.fi, Sofiev et al., 2006, 2008) for diagnostic assessment and forecasting of the atmospheric composition. This SILAM application also enables the indirect verification 
of the FAS itself via comparison of modelled concentrations with in-situ and remote-sensing observations.

\section{Description of the Fire Assimilation System (FAS)}

The FAS is based on Level 2 MODIS Collection 4 and 5 Active Fire Products, which are used for the near-real-time and historical evaluation of the emissions from wild-land fires. The FAS information is processed into the emission input for the atmospheric composition modelling system SILAM for a subsequent evaluation of the impact of fires on atmospheric composition and air quality.

The present FAS consists of two parallel branches based on partly independent products: the Temperature Anomaly and Fire Radiative Power. Their algorithms of converting the fire information to the emission fluxes of atmospheric pollutants are described below, starting from the outlines of the corresponding fire products.

\subsection{Background}

\subsubsection{The fire detection algorithm of the MODIS instrument}

The MODIS fire detection procedure is based on a contextual algorithm of Giglio et al. (2003) that exploits the strong emission of mid-infrared radiation from fires (Dozier, 1981; Matson and Dozier, 1981). The algorithm examines each pixel of the MODIS swath and attributes it to one of the following classes: missing data, cloud, water, non-fire, fire, or unknown. For each fire-classified pixel, the procedure attempts to use the neighbouring pixels to estimate the radiometric signal of the pixel, if there would be no fire there. Valid neighbouring pixels are identified in a window centred on the potential fire pixel and used to estimate this background value.

If the characterization of the background is successful, a series of threshold tests are used to confirm the active-fire hypothesis. These search for the characteristic signature of an active fire, in which both the $4 \mu \mathrm{m}$ brightness temperature and the difference between the 4 and $11 \mu \mathrm{m}$ brightness temperatures depart substantially from those of the non-fire background. The thresholds are adjusted based on the natural variability of the background. Additional tests are used to eliminate false detections caused by sun glint, desert boundaries, and errors in the water mask. Candidate fire pixels that are not rejected in the course of these tests are assigned with the class of fire. A dedicated effort is needed to separate the wild-land fires from other types of fires, which is done on the basis of the land use reported for the detected fire pixel.

\subsubsection{Outline of the test cases used for the development and testing of FAS}

The FAS was developed and evaluated on the basis of a set of fire episodes, which were selected from actual MODIS records during recent years. The selection criteria were: (i) well identified fire sources and limited impact of clouds, (ii) easily distinguishable fire plumes dominating over those of other sources, (iii) sufficient duration of the episode (a week or more) to average out the random fluctuations in the model simulations, and (iv) the representativeness of the complete set of episodes at a European scale.

The episode 1 occurred in spring 2006 and caused a severe deterioration of air quality over a major part of Europe (Saarikoski et al., 2007; Stohl et al., 2007; Sofiev et al., 2009). It lasted for most of April and May of 2006 while the highest ground-level concentrations were recorded during 25.04-10.05.2006. During the first part of April, an unusually hot and dry period with low-wind conditions contributed to an accumulation of the anthropogenic contamination over Eastern Europe. It was accompanied by widespread wildland fires over western Russia. The burning material mainly consisted of previous-year grass remnants, which were dried up by the beginning of the fires. However, the emissions from forest and mixed areas were also substantial (Figs. 1 and 2). Resulting mixture of pollutants was transported over the whole Europe in the beginning of May reaching Spitsbergen and Iceland and causing severe degradation of air quality. High concentrations of several pollutants were registered along the plume passway. The episode was finished by a frontal rain passing over Europe from the Atlantic, which scavenged out the pollutants, and largely extinguished the fires.

The episode 2 took place in August 2006 and was geographically located in two regions: in Northern Europe (the Russian part of Karelia, Estonia and Finland) and in SouthEastern Europe. The burning material was a mixture of grass, agricultural remnants (mainly in the south), but also bog and forest trees (mainly in the north) (Fig. 2). We have considered here the fires in the northern region, where pit fires and, to a smaller extent, forest fires created a set of very dense plumes, which were important on regional and meso-scales.

The episode 3 took place in August of 2008, mainly in the Ukrainian and Russian territories, but also over Moldova, Romania, Bulgaria and Greece. The burning material was mainly grass and regional forests. The fire smoke was transported in several separated pollution clouds to the north and to the east. To our knowledge, this episode has not been studied, probably as practically no in-situ observations have been internationally available up to date. Such fires occur almost every year in that region commonly lasting for most of August. However, few studies have been published regarding these fires. In 2008, the plume was transported towards the north-east and could not be observed by the Western 

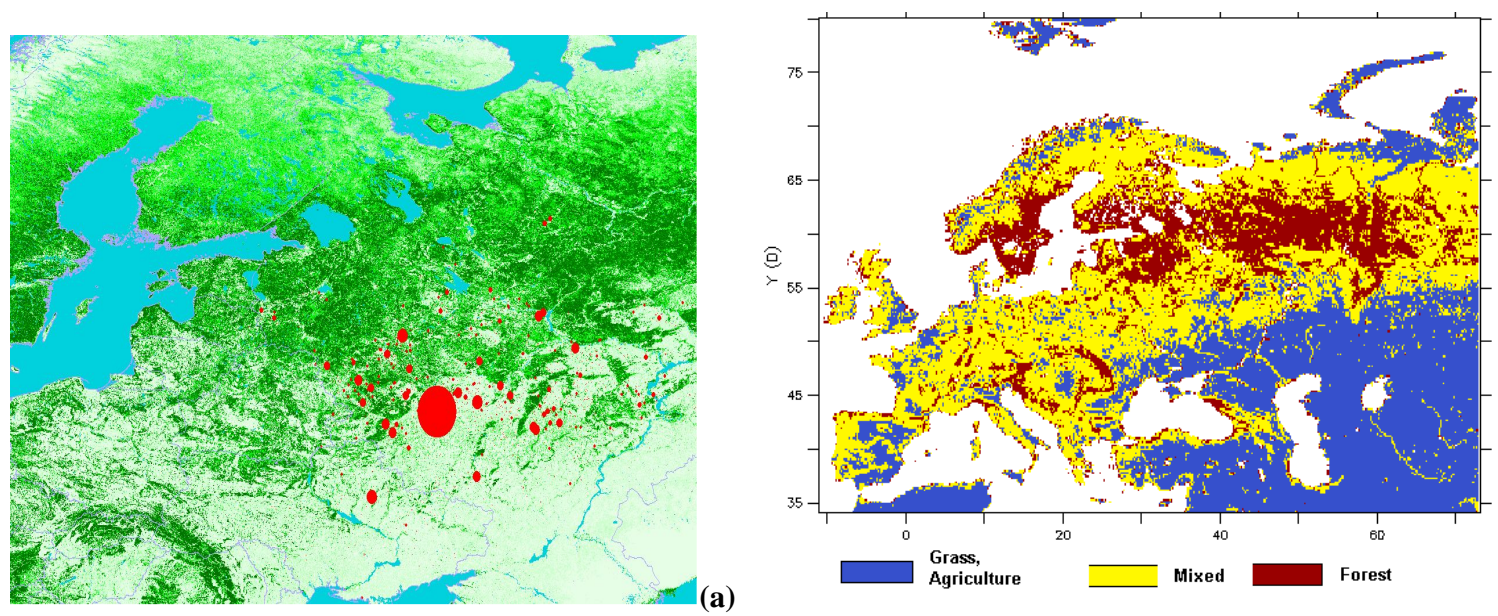

(b)

Fig. 1. (a) the LANDSAT land cover inventory, on a spatial resolution of $250 \mathrm{~m}$; examples of fires in May 2006 are shown as red dots, their diameters are proportional to the Fire Radiative Power. (b) The classification of prevailing land types on a resolution of $10 \mathrm{~km}$, as a surrogate for emission factors (constructed from the data of LANDSAT and USGS-2).

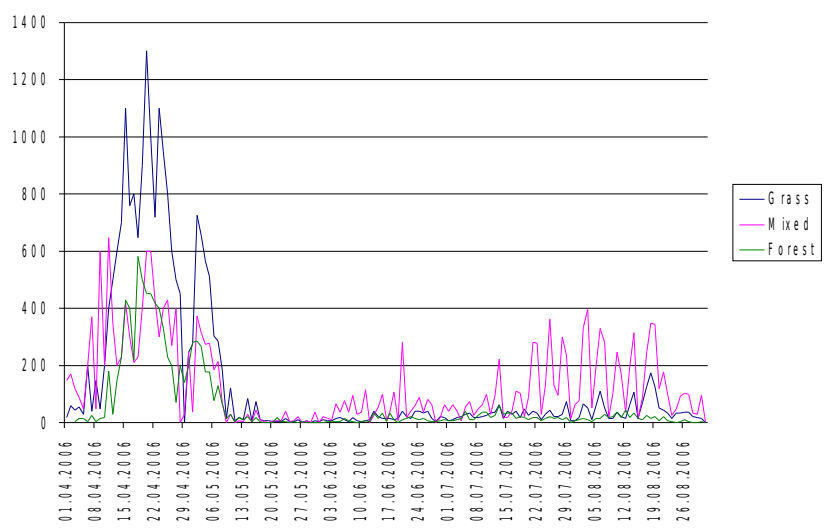

Fig. 2. Temporal evolution of fire FRP [MW] distributed between the land use types for the fire season of 2006. The geographic area considered is the whole of Europe (the same as in Fig. 1b).

European observational networks. We have therefore used satellite retrievals to describe the event.

Regarding these episodes, the best-observed one is case 1 , as its smoke was recorded by a number of European air quality stations. Case 2 was mainly detected by the Finnish observational sites. The case 3 analysis has to rely on the satellite information. Its advantages, however, are the wellidentified plumes, which were transported over regions with comparatively low anthropogenic emissions, thus reducing the impact of the anthropogenic emissions to the concentrations.

The overall representativeness of the cases on a European scale was qualitatively estimated on the basis of the type of the fuel burning rather than from the geographical position of the fires. Thus, case 1 represents a dry grass fire, case 2 is mainly a bog and boreal forest fire, and case 3 is a mixture of the present-year grass (partly dry, partly still green) and the sub-tropical forests.

In addition to the episodes, the FAS was also executed for the complete three-yearly period from 2006 to 2008 on a daily resolution, in order to obtain the long-term averages that could possibly be compared with the corresponding values obtained in other fire emission inventories.

\subsection{The evaluation of $\mathbf{P M}_{2.5}$ emission based on Temperature Anomaly (TA) products}

For simple fire-detection purposes, the fire-classified pixel is attributed with the $4-\mu \mathrm{m}$ brightness temperature $T_{4}$ (this channel is the most-representative and least affected by other factors that are not connected with fires). The method is also known as hot-spot counting and the pixel temperature is further referred to in this study as the TA-value.

The simplicity of this product and its operational availability allowed its utilization as a starting point for FAS development. This branch is hereinafter referred to as FASTA. The system receives the input from ASCII telegrams that contain the location, the temperature and the detection confidence of the thermal anomalies. This brightness temperature is then multiplied with an empirical coefficient of 6.78 ton $\mathrm{PM}_{2.5} \mathrm{yr}^{-1} \mathrm{~K}^{-1}$ to yield an emission flux of $\mathrm{PM}_{2.5}$. The scaling was obtained for the Western-Russia (mainly) grass-fire episode 1 in 2006 (Saarikoski et al., 2007, hereinafter referred as S07). Input data for the calibration were: (i) the MODIS hot-spot counts (temperature anomaly product) collected over an extensive territory in Western Russia (about $1000 \mathrm{~km} \times 1000 \mathrm{~km}$ ) with a resolution of $1 \mathrm{~km}$, (ii) near-surface observations of $\mathrm{PM}_{2.5}$ concentrations in Finland, located directly downwind from the fire at the distances of about $500-600 \mathrm{~km}$. These two datasets were related via 
FAS-TA and dispersion model SILAM, finally yielding the TA emission factor for $\mathrm{PM}_{2.5}$.

The $\mathrm{PM}_{2.5}$ emission fluxes can be converted further to total PM, as well as to other species using the factors of Andrea and Merlet (2001, hereinafter referred as AM01).

The advantages of FAS-TA are its simplicity and the nearreal-time (NRT) availability of the data via Rapid Response System (with a delay of just a few hours), which allow its fast application. Also, the system is sensitive to small-scale fires. However, the information obtained from the TA value is limited since the algorithm neglects the background temperature of the fire pixels and uses a simple scaling from temperature to emission rate.

\subsection{The evaluation of total PM emission based on Fire Radiative Power (FRP) products}

For more sophisticated reporting, the MODIS product list includes the Fire Radiative Power (FRP, a rate of release of Radiation Energy, FRE) of the fire pixel, based on the empirical formula of Kaufman et al. (1998):

$\mathrm{FRP}=4.34 \times 10^{-13}\left(T_{4}^{8}-T_{4 b}^{8}\right)$, [Watt $]$

where the $T_{4}$, and $T_{4 b}$ are the fire and the background (taken from neighbouring pixels) temperatures, respectively, measured at the $4-\mu \mathrm{m}$ channel. The dependence has been obtained from fitting the actual release of radiative energy from a fire and its apparent temperature at the 4 and $11 \mu \mathrm{m}$ channels - as observed by the MODIS instrument. The relationship showed good correlation for open moderate-to-strong fires (Kaufman et al., 1998). There may be potential difficulties for small fires, as these may be partly overshadowed by trees, appear as low-temperature but strongly emitting smouldering fires, etc.

As TA, the FRP data are included into the level 2 Fire Products (MOD14 for Terra and MYD14 for Aqua satellites) and are available with a comparatively short delay (usually within 1-2 days), which makes it possible to utilise them within the FAS. However, until recently, FRP has not been available via the Rapid Response System that is practically NRT and updated several times a day. This can cause additional delays in case of technical problems at the central processing or distribution sites. Such delays affect the applicability of the FRP product for the needs of the operational monitoring system.

To convert the FRP to emission fluxes we used a similar approach as for TA - a direct conversion of FRP using an empirical scaling to emission rates. In the current FAS it is based on Ichoku and Kaufman (2005, hereinafter referred as IK05) who related the FRP in [W] per pixel to total particulate matter $(\mathrm{PM})$ emission in $\left[\mathrm{kg} \mathrm{tPM} \mathrm{s}^{-1}\right]$. Since the calibration IK05 was obtained by relating the aerosol optical depth (AOD) with the FRP, the obtained emission factors are valid for total $\mathrm{PM}$ instead of $\mathrm{PM}_{2.5}$, which was the reference species for FAS-TA. The mean relation between these PM measures can be evaluated based on AM01: within the fire plume

$m_{p m_{2.5}} \approx 0.6 m_{\text {total pm }}$

The relation is approximately valid for all land use types: the changes between the vegetation types are smaller than the uncertainty range within each type (AM01).

The key parameter for FAS-FRP is therefore the emission rate of total PM per unit FRP, i.e. the smoke emission factor $C_{e}\left[\mathrm{~kg} \mathrm{tPM} \mathrm{J}^{-1}\right]$. According to IK05, $C_{e}$ varies from $0.02-$ $0.06 \mathrm{~kg} \mathrm{tPM} \mathrm{MJ}^{-1}$ for boreal regions, $0.04-0.08 \mathrm{~kg} \mathrm{tPM}$ $\mathrm{MJ}^{-1}$ for Africa (mainly savannas and grassland), and 0.08 $0.1 \mathrm{~kg}$ tPM MJ ${ }^{-1}$ for Western Russian regions. Since the $C_{e}$ determination involved a simple estimate of atmospheric transport (based on wind at a constant height and not involving a dispersion model), the authors suggested that the coefficients are probably overestimated by about a factor of 2 . Using these estimates as a starting point, we have developed the emission coefficients that are based on actual land-cover information, instead of geographical region.

\subsection{Connecting the FRP emission factors and the land use}

The procedure of linking the FRP products with the land-use was made in three steps with subsequent 4th step verifying the obtained calibration:

1. the LANDSAT land use inventory for Europe with $250 \mathrm{~m}$ resolution and USGS with $1 \mathrm{~km}$ grid spacing were aggregated to the map of the vegetation fractionation with $10 \mathrm{~km}$ resolution. It included only three types of land use: grass and agriculture land, forests, and a mixture of these (Fig. 1);

2. for these three types, we assumed the following totalPM emission coefficients: $0.1 \mathrm{~kg} \mathrm{tPM} \mathrm{MJ}^{-1}$ for forest, $0.05 \mathrm{~kg} \mathrm{tPM} \mathrm{MJ}^{-1}$ for grass/agriculture lands, and an average of $0.075 \mathrm{~kg} \mathrm{tPM} \mathrm{MJ}^{-1}$ for mixed areas. These values were deduced from the prevailing land cover in the IK05 domains;

3. these coefficients were adjusted using the fire episodes 1 and 2, for which the actual location of each daily fire pixel was attributed to one of the land cover types (see Fig. 2 for the total-FRP release from each land-use class). The emission maps were used as input data by the chemical transport model SILAM, which simulated the atmospheric dispersion of the plumes. The results were compared with the MODIS observations of AOD and the coefficients for the corresponding source types were adjusted.

4. Finally, the $\mathrm{PM}_{2.5}$ concentrations computed by the SILAM model were compared with observations of 

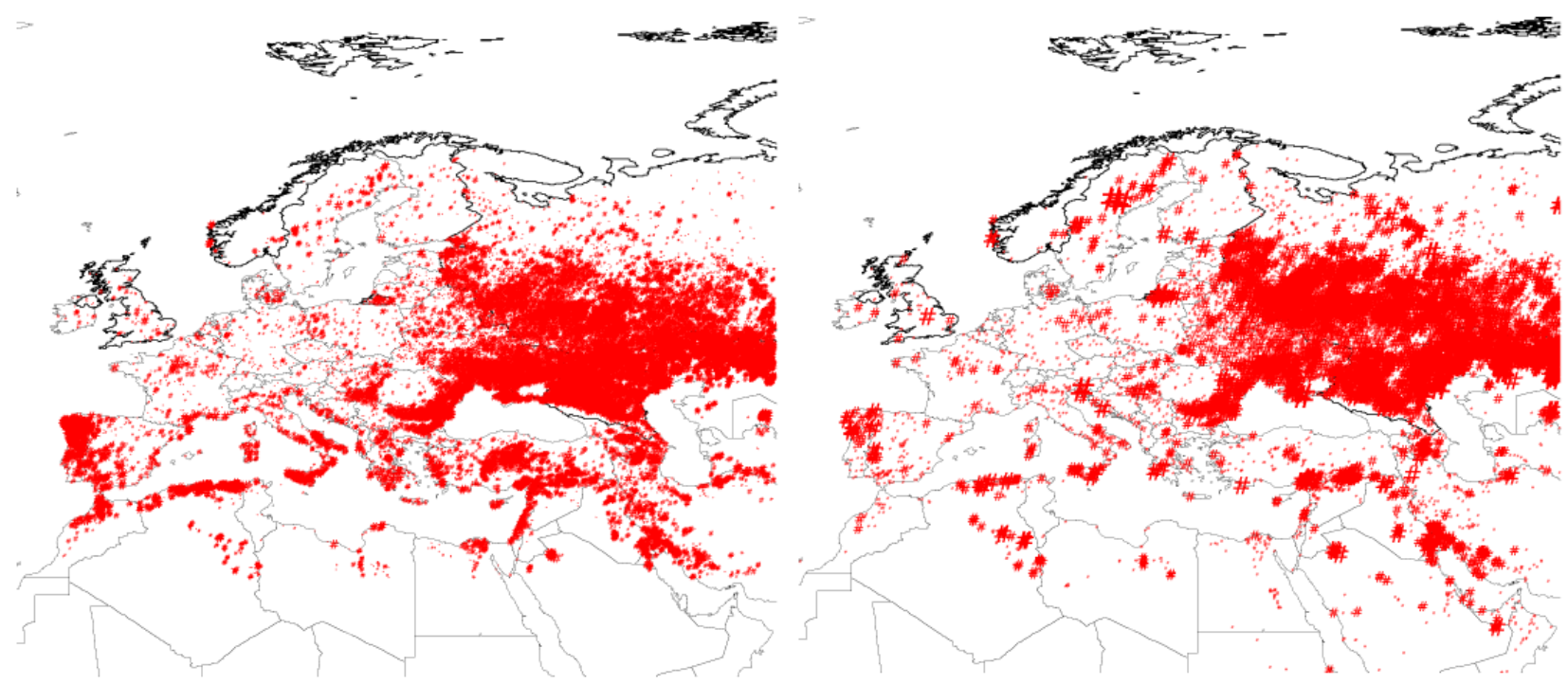

Fig. 3. TA- (left-hand panel) and FRP- (right-hand panel) characteristics of the fires in 2006. All observed fires are presented. The linear sizes of the markers are proportional to the corresponding TA/FRP values.

the Finnish stations of Helsinki-Kumpula (urban background), Uto (regional background), Virolahti (regional background), Oulu (small city, urban background) and Vaasa (small city, urban background).

The reference dataset used for the calibration was the aerosol optical depth from MODIS, converted to the total columnintegrated PM concentrations (an extension of the MODIS AOD product available e.g. via Giovanni framework http: //daac.gsfc.nasa.gov/techlab/giovanni). This dataset was utilised for setting the numerical values of the emission factors. The reason for using the satellite observations as the main source of information for the calibration of FAS is that the modelled near-surface concentrations are sensitive to the treatment of the boundary layer in the model. In addition, the ground-based observational network is comparatively scarce and there are potential uncertainties due to the limited spatial representativeness of the sites (Galperin and Sofiev, 1994).

We assumed that inside the fire plumes, the AOD was entirely determined by the biomass-burning products. It is partly supported by $\mathrm{S} 07$ analysis, as they found that more than $80 \%$ of $\mathrm{PM}_{2.5}$ during a specific episode in May 2006 was originated from fires. We therefore attributed all systematic discrepancy between the observed and calculated column AOD to errors in the emission rates, and corrected the emission factors accordingly.

The resulting emission coefficients for the European domain are the following: $0.035 \mathrm{~kg} \mathrm{tPM} \mathrm{MJ}^{-1}$ for forest, $0.018 \mathrm{~kg} \mathrm{tPM} \mathrm{MJ}^{-1}$ for grassland and agriculture, and $0.026 \mathrm{~kg} \mathrm{tPM} \mathrm{MJ}^{-1}$ for mixed areas.

Analysis of the $\mathrm{PM}_{2.5}$ and $\mathrm{PM}_{10}$ concentrations obtained with the updated emission factors are discussed in the Sect. 4.

\subsection{Cross-calibration of the FAS-TA and FAS - FRP}

The FRP is physically a better grounded quantity than TA for the determination of the fire emissions: the release of radiative energy is indeed approximately proportional to the number of carbon atoms oxidised per second. Compared to that, the dependence of the brightness temperature on the fire intensity is much less straightforward. It is also more affected by factors that are not directly associated with the fires per se (such as the meteorological ones). Consequently, the TA value should be less sensitive to the fire intensity and have a weaker connection to the emission.

Figure 3 illustrates these differences using the European fires in 2006 as an example. Both panels include all the fires recorded during 2006 with the marker linear dimension proportional to TA (left-hand panel) and FRP (right-hand panel). As one can see, the TA mechanism is much less sensitive to the intensity of a single fire; it reports most of them to be approximately the same intensity. The FRP products reflect better the diversity in the magnitude of the fires, but may under-predict the small fires, many of which are presented on the map as very small dots.

However, also the FRP methodology has inherent limitations. Firstly, Eq. (1) is obtained not via rigorous derivations but via empirical fitting to observations, which makes it dependent on the specific characteristics of the measured data. Secondly, it is presently available only from a few instruments. TA, to the opposite, is available from a wide range of instruments and satellites. Thirdly, the $11-\mu \mathrm{m}$ channel needed for the computations and for distinguishing between the types of burning is noisy. Fourthly, the reliance on neighbouring pixels for evaluating the background temperature of the burning one can lead to problems, especially in 

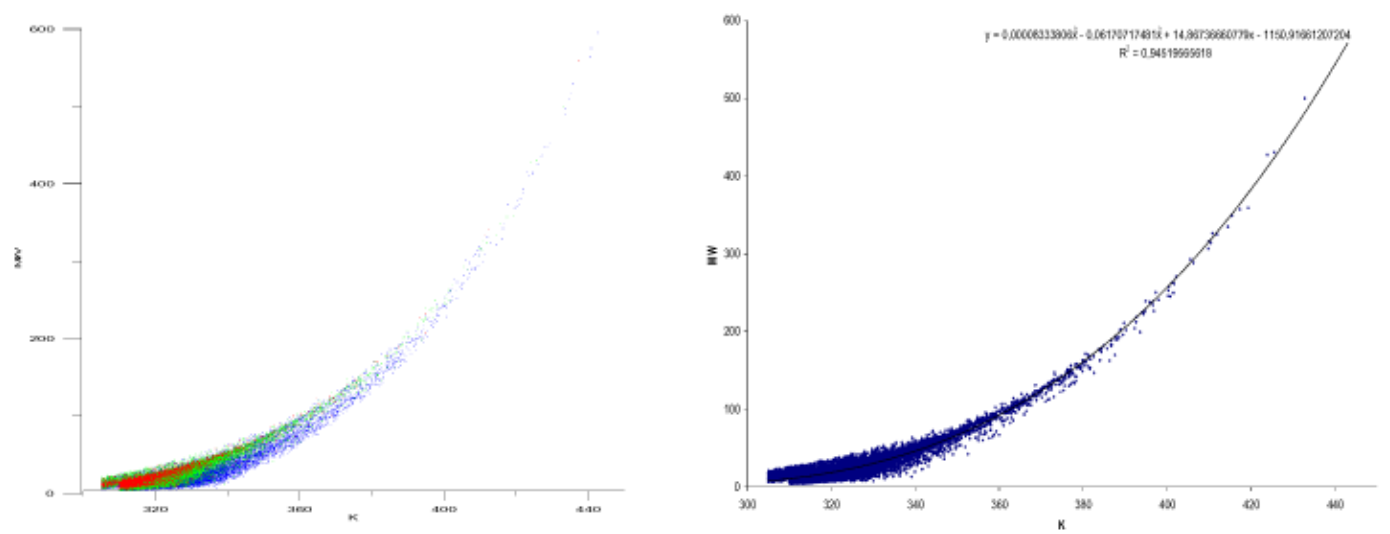

Fig. 4. Left-hand panel: The relation between the brightness temperatures, [K] from 21-st band of MODIS (horizontal axis) and FRP for the same fire pixel from MOD14 fire product [MW per pixel area] (vertical axis). Colours of the dots correspond to the land cover types (red forest, green - mixed forest and grass, blue - grass only). Right-hand-panel: the land-use-independent fitting Eq. (3) and the forest-fires data sub-set.

the regions with heterogeneous land use or densely located fires occupying several grid cells. Fifthly, the 8th power of temperatures in Eq. (1) makes the final estimates sensitive to inherent noise in the temperature observations. Finally, due to the use of a more sophisticated algorithm, the near-realtime availability of FRP from MODIS was worse than that of TA, reported through the Rapid Response System.

Observing small fires is a special problem, where the combined use of both TA and FRP methods can be efficient. The differences of the 8th powers of temperatures become uncertain, when the burning-pixel and background brightness temperatures approach each other. For such cases, also the chemical composition and the particle size distributions of the emission fluxes are most likely different, compared with the larger scale fires, as the burning becomes less efficient. For smaller fires, the relative fraction of $\mathrm{CO}_{2}$ is expected to decrease, and the $\mathrm{CO}$, soot and coarse aerosol fractions are expected to increase. As a result, the emissions of coarse aerosols and other trace species related to incomplete combustion processes would be disproportionally larger for small fires, i.e., the FRP and the emission fluxes should be modelled with a less steep temperature dependence than the 8th power. Whether the actual power should be 1, as in TA approach, or something intermediate remains open but it is evident that for small fires, the TA value is closer to the upper estimate of the possible emission rates, and the FRP value closer to the lower one.

It is therefore reasonable to consider the inter-dependence of the predictions of the FAS-TA and FAS-FRP algorithms. For this purpose, we used the dataset of episode 1 (in 2006) and also took into account the split between the three landuse types.

As seen from the scatter plot of FRP against TA values (Fig. 4a), there is a functional dependence between these products, with very narrow spread for moderate and strong fires. The noticeable scatter of data for small fires was to be expected. Indeed, besides the above-mentioned methodological difficulties in case of small fires, the TA method does not allow for the background temperature, which becomes comparable with the actual temperature of the pixel if the fireinduced heat release is small. However, the segmentation of the data in terms of the land use types significantly improves the correlation, even for small fires (Fig. 4a, b).

The strong connection between FRP and TA and the small scatter allow polynomial fitting of TA to FRP (Fig. 4b), which appears valid for all land-use types:

$\mathrm{FRP}=8.3338 \times 10^{-5} \times \mathrm{TA}^{3}-6.11707 \times 10^{-2} \times$
$\mathrm{TA}^{2}+14.8674 \times \mathrm{TA}-1150.92$

where TA is in $[\mathrm{K}]$ and FRP is in [MW].

The relation between the observed FRP and the FRP computed from TA using Eq. (3) is practically linear, with the regression slope deviating from unity by $\sim 2 \%$ and the correlation coefficient of $\sim 0.94$ for all land use types. Hence, the values of TA can be converted to FRP with a good accuracy, if the latter ones are unavailable or doubtful.

\subsection{Operational setup of FAS at FMI}

The current section outlines the implementation of the FAS at Finnish Meteorological Institute and its connections with the air quality modelling. The implementation required solutions of several problems whose detailed descriptions are out of the scope of the current paper. Therefore, the presented outlines aim only at a general outlook, which is relevant for interpreting the FAS application and evaluation results shown in the next sections.

The operational FAS setup includes both TA- and FRPbased branches constructed in a complementary way. For the 
periods when both TA and FRP are available, the branches are kept independent. Each uses its own linear scaling to emissions of $\mathrm{PM}_{2.5}$ and total $\mathrm{PM}$, respectively, which are then scaled to a full list of chemicals according to AM01. For days, in which the FRP data are either unreliable or do not exist, the system converts TA to FRP using the fitting Eq. (3). This FRP substitution is treated the same way as the original FRP: scaled to total PM emissions and then to the fluxes of other species.

Atmospheric composition forecasts require also forecasts of the evolution of the fires. Presently, these are based on the persistency assumption: the observed fires are assumed to continue for the whole forecasting period $(48 \mathrm{~h})$ with a constant mean intensity equal to the latest recorded level. This simple assumption nevertheless qualitatively reflects two important features: fires that are observed at some moment will continue burning at least several more hours - even in case of a fire brigade intervention. Secondly, even an extinguished fire keeps smouldering for some hours or days; it is therefore still a source of pollutants (clearly, with a different emission rate).

A significant challenge for the current FAS algorithm is the modelling of the diurnal variation of the fire intensity. The main source of information - the MODIS instrument onboard of Aqua and Terra satellites - can provide only 2-4 values per day per place and only during daytime. This is evidently insufficient for the quantitative representation of the diurnal variation. Therefore, we assumed a conservative diurnal variation, same for all types of vegetation and regions, which suggests day-time emission intensity to be $25 \%$ higher than the daily-mean level while the night-time emission is $25 \%$ lower (Saarikoski et al., 2007). The actual variation is probably larger and depends on land-use and meteorology (e.g., Beck and Trevitt, 1989; Beck et al., 2001); however, the up-to-date available information on the diurnal variation of the fires is scarce.

The fire-induced PM emission obtained from each FAS branch is merged with other pollution sources taken into account by the SILAM model dispersion simulations - as maps of gridded daily-mean emission rates with superimposed fixed diurnal cycle. The extension of PM emission to other species used the AM01 factors. We assumed that the following admixture of gaseous species is emitted in addition to PM: $94 \%$ of $\mathrm{CO}, 1.3 \%$ of $\mathrm{HCHO}, 2.9 \%$ of $\mathrm{NO}_{\mathrm{x}}$ as $\mathrm{NO}_{2}$, $1.4 \%$ of $\mathrm{NH}_{3}$, and $0.4 \%$ of $\mathrm{SO}_{2}$ (mass fractions as species). The gaseous emission flux is assumed to be 7.9 times larger than the particulate mass flux. These fractions are assumed to be valid for all European land use types.

An effort is made to avoid double-counting of the secondary PM. The FAS calibration against MODIS AOD reports all the secondary aerosols as primary emission. A potential way to reduce this effect is to consider the calibration as close as possible to the fires themselves, so that the transport time is short and production of secondary aerosols is limited. That procedure, however, is prone to other un- certainties. The above mentioned regional-scale calibration, having less noise due to spatial and temporal averaging, over-estimates the primary PM emission due to misinterpreting the secondary aerosols as primary ones. According to SILAM chemical simulations, this typically amounts to $\sim 20 \%$ of the total aerosol mass.

The SILAM modelling system (Sofiev et al., 2006, 2008) currently includes both Lagrangian and Eulerian dynamic kernels. It takes into account up to 8 different types of the transported species including size-segregated aerosol, sulphur and nitrogen oxides and some VOCs. Operationally, it is used to predict sulphur and nitrogen oxides, ammonium, some hydrocarbons, ozone, sea salt, fine and coarse primary anthropogenic aerosols $\mathrm{PM}_{2.5}$ and $\mathrm{PM}_{10}$, as well as biogenic primary aerosols, such as pollen. Other compounds are utilised only in research applications. The current study is based only on the Eulerian-kernel computations with the SILAM v.4.5.1.

Injection height for all fires is prescribed. According to available literature data (Trentmann et al., 2006; Freitas et al., 2007; Zilitinkevich et al., 2006; Labonne et al., 2007; Mazzoni et al., 2007; Kahn et al., 2008, etc), simulations with the BUOYANT plume-rise model (Nikmo et al., 1999), the US fire injection height archive derived from MISR observations over the US (Mazzoni et al., 2007) the plumes from small or moderate fires rarely rise higher than twice the height of the boundary layer $H_{\mathrm{ABL}}$ being in most cases confined within $0.5-1$ of $H_{\mathrm{ABL}}$, especially if it is deep. For a qualitative consideration, Fig. 9a shows that the fires in the MISR climatology ( $>500$ fires analysed over several years) set are much stronger than the fires comprising the episodes 1 and 3 (over 23000 individual fires, case 2 excluded, as these fires were small). The MISR fires, however, extremely seldom inject plumes above $1.5-2 \mathrm{~km}$ (a typical ABL height for summer at those latitudes) and the dependence of the altitude on FRP is weak (Fig. 10b). The quantitative comparison of MISR archive and European fires is not straightforward due to different methodologies behind the sampling and possible bias of MISR dataset towards stronger fires (for which the plume height analysis is more precise). We therefore conclude that (i) the injection of smoke from moderate fires in most cases takes place within the boundary layer, and (ii) European fires, even in strong events considered in the current study, can be classified as moderate ones. For the European fires we therefore assumed simply that $50 \%$ of the emissions are injected in the lowest $200 \mathrm{~m}$, and the rest is homogenously distributed from $200 \mathrm{~m}$ up to $1 \mathrm{~km}$.

\section{Examples of the simulations and comparison with the MODIS and ground-based observations}

Two examples of the simulations for the episodes 1 and 3 are shown in Figs. 5 and 6. In both figures, the panel a) presents the SILAM computations with only FAS-TA emission fields 

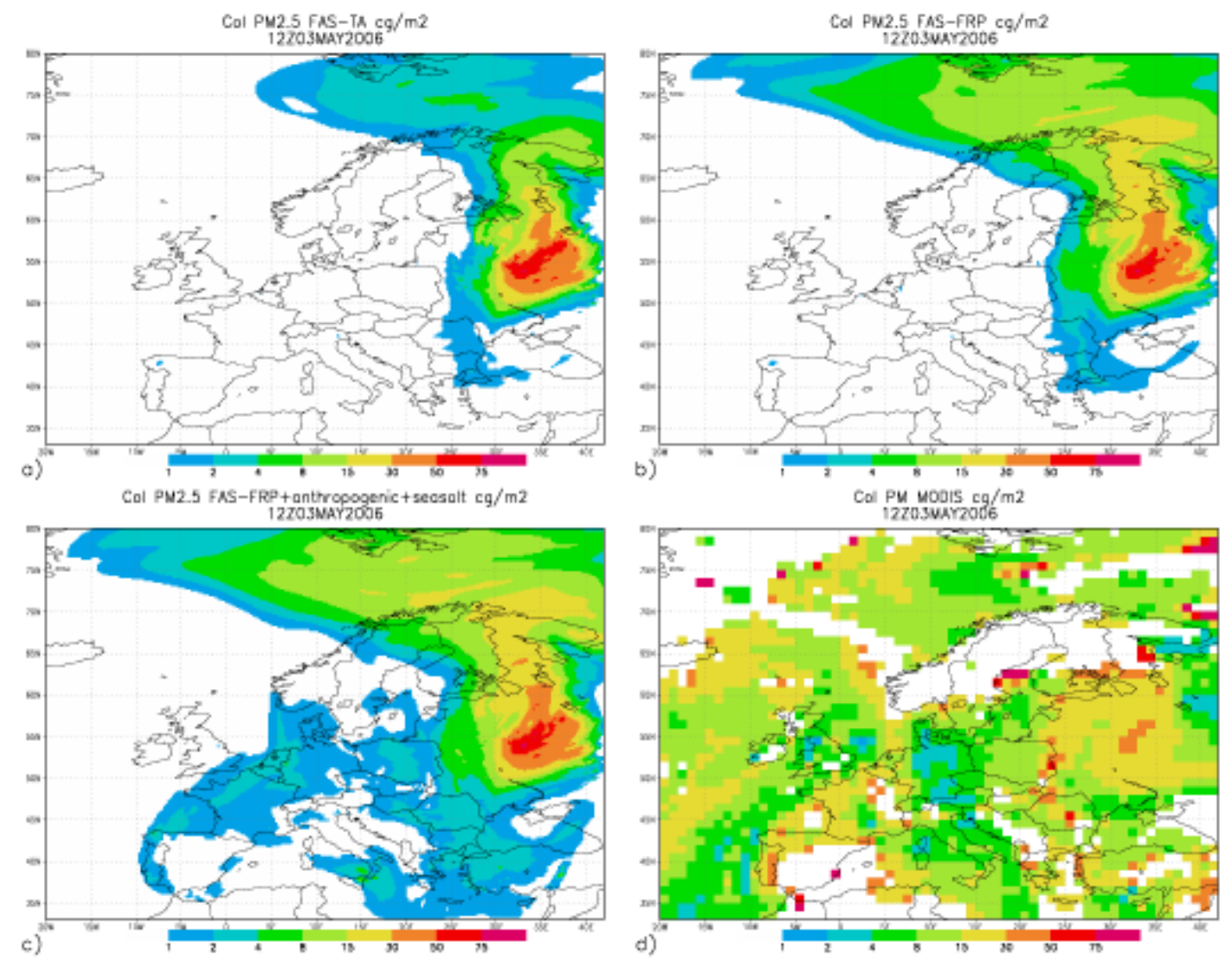

d)

Fig. 5. Spatial distribution of column-integrated $\mathrm{PM}_{2.5}$ concentration on 3.5.2006. (a) The SILAM simulations with only FAS-TA PM 2.5 emissions, (b) The SILAM simulations with only FAS-FRP PM 2.5 emissions, (c) The SILAM simulations for total PM 2.5 for full emissions, and (d) combined MODIS Aqua and Terra observations (processing: Giovanni system, Acker and Leptoukh, 2007). Unit: [cg PM $2.5 \mathrm{~m}^{-2}$ ].

for $\mathrm{PM}_{2.5}$, the panel $\mathrm{b}$ - for only FAS-FRP emission, the panel $\mathrm{c}-$ for the full emission including total PM from FASFRP combined with anthropogenic and natural sources, and the panel $\mathrm{d}$ is obtained from merged MODIS Aqua and Terra aerosol column-integrated mass over land.

The full-emission SILAM simulations included anthropogenic, natural sea salt emissions and fire-induced emissions for $\mathrm{SO}_{\mathrm{x}}, \mathrm{NO}_{\mathrm{x}}, \mathrm{NH}_{\mathrm{x}}$ and some organic species. In case of fires, the speciation was based on the AM01 fractions. The spatial resolution of the simulations was $25 \mathrm{~km}$ with 10 vertical layers up to $\sim 8 \mathrm{~km}$ of the altitude. The resulting gaseous and particulate compounds have been converted to AOD and to total-PM column-integrated burden.

Analyzing the results for both cases, one has to allow for the following inherent limitations in modelling and experimental data. Firstly, the model emission fields did not include wind-blown dust, which, however, is expected to be small in comparison with the fire plumes. In addition, the actual MODIS observations of Aqua and Terra take place with a time lag: satellites fly over Europe at different times, about two hours one after another. Since each overpass covers only a part of the computational domain, the complete map is actually a compilation of several overpasses, also about $1.5 \mathrm{~h}$ after each other, but all the observations refer to daytime (mostly in the morning). This results in certain imbalance of the merged AOD fields: they are shifted in time from each other and their combination has no definite time tag. Therefore, the model results in Figs. 5 and 6 are averaged over the daytime. Finally, observations cannot provide any information for the areas covered by clouds or by dense aerosol plumes (often for fires) misinterpreted as clouds - these areas are missing in the panels $\mathrm{d}$ of both figures. 


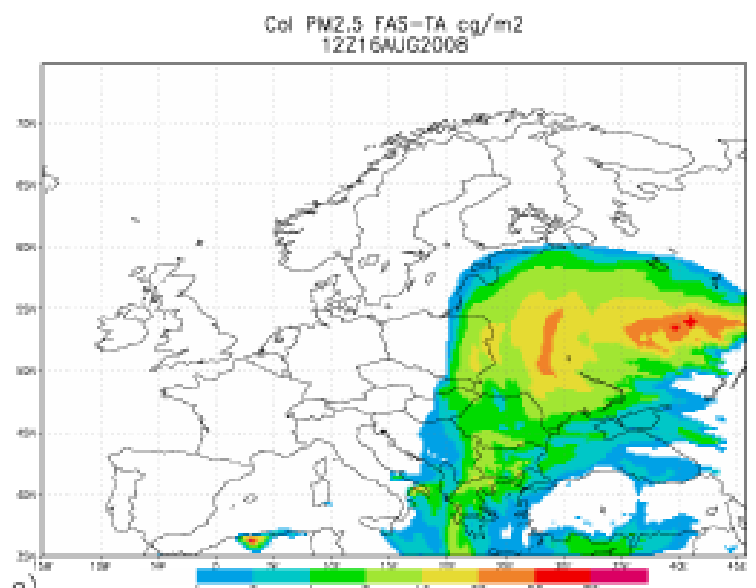

a)
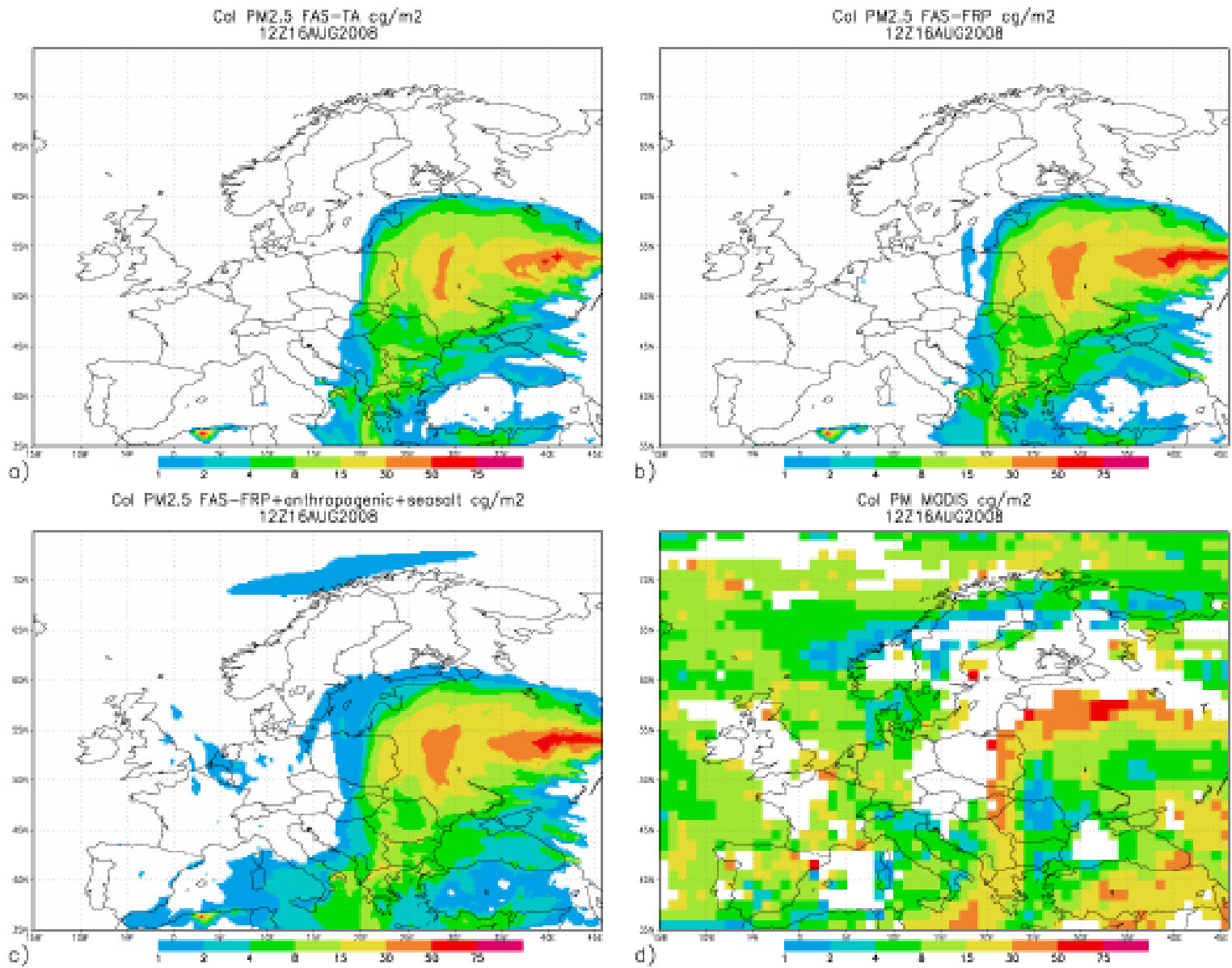

Fig. 6. Spatial distribution of near-surface concentration of $\mathrm{PM}_{2.5}$ 16.8.2008. (a) is for SILAM simulations with only FAS-TA PM 2.5 emission, (b) is for the run with only FAS-FRP PM 2.5 emission, (c) is the total-PM 2.5 for full-emission computations, (d) is combined MODIS Aqua+Terra observations of total PM mass in column (processing: Giovanni system, Acker and Leptoukh, 2007).

For both cases, the absolute levels of predicted columnintegrated PM mass differ by approximately $30 \%$ from the observations (e.g. in Fig. 5 slightly over $50 \mathrm{cg} \mathrm{m}^{-2}$ in the predicted peak compared with $\sim 35 \mathrm{cg} \mathrm{m}^{-2}$ observed while in Fig. 6 both the model prediction and MODIS observations show around $30-50 \mathrm{cg} \mathrm{m}^{-2}$ (however, the peak locations are somewhat shifted). The shapes of the predicted and measured fire plumes are qualitatively similar, except for the northern part of the fire plume in 2006, where it mixes-up with the anthropogenic pollution from Central and Eastern Europe and is also partly overshadowed by clouds. In both cases, the SILAM-predicted max column burden is larger than the observed one, which might point at over-stated fire emission coefficients. However, the predicted plumes are less efficiently dispersed than the observed ones, which seem to cover larger areas. The reasons for these differences can be either inaccuracies in the dispersion estimation or the above-mentioned difficulties with the observations. Finally, the over-estimation was not systematic day-by-day although seen more often than the under-estimation.
To build a scatter-plot of the FAS+SILAM agreement with the MODIS observations for each day of the episode 1, an area with dominating fire-induced pollution has been selected out of the domain and the scatter plots were made for each day; an example of such figures has been presented in Fig. 7. The day-to-day variation was large but the scatter itself was moderate: each plot contains more than 4500 points, so that the visible spread in Fig. 7 with distinguishable individual points constitutes less than $0.1 \%$ of the total set. Comparing the scatter plots in Fig. 7, one can also notice the similarities and differences between the results of FAS-TA and FAS-FRP. Both plots show smaller scatter for low concentrations in the columns, both have a very dense cloud of points with almost twice over-estimation of concentrations at $\sim 10 \mathrm{cg} \mathrm{m}^{-2}$; finally, both systems result in certain under-estimation of the maximum values. However, the TAbased scatter plot (left) has a higher correlation (0.5) compared with that of FRP (0.3). This is mainly due to stronger non-linearity seen in the FPR-based plot: somewhat stronger over-statement of the moderate concentrations and somewhat 
stronger under-estimation of the peaks. However, such dependencies did not repeat every day, so we do not draw definite conclusions on the relative performance of the branches.

Comparison with in-situ observations was also performed using the available information for 2006 (the case of August 2008 does not have enough data available to justify such comparison). An example of evaluation against AIRBASE stations (http://www.eea.europa.eu) is shown in Fig. 8, which depicts the beginning of the plume motion towards the west. During the next few days it has reached the Atlantic and Iceland. On 5 May, one can clearly see two well-segregated parts of the European pollution pattern: the anthropogenic contamination over France, Benelux and Germany on the west, and Eastern Europe, which is covered by a dense fire smoke.

\section{Discussion}

The Fire Assimilation System presented above is based on a simple set of assumptions and involves explicit scaling factors to convert the TA or FRP values to the emissions of particulate matter and other pollutants. The approach is similar to that of Ichoku and Kaufman (2005) whose emission factors were used as the initial set. However, in that work the assumptions regarding the transport of smoke from the fires were simpler. According to the authors, such simplification results in uncertainties in the emission coefficients of about a factor of 2, with a probable over-prediction of the emission factor $C_{e}$.

In this study, detailed atmospheric transport simulations were performed and the scaling coefficients were attributed to the type of the land use rather than to the geographical position of the region.

According to the present study, the IK05 $C_{e}$ values for the European area are indeed over-estimated but somewhat more than expected. On the average, the new emission factors are 2-3 times lower - and the model still tends to over-predict the aerosol column burden with both the FAS-TA and FASFRP emissions. This is seen from evaluation of the independent cases with the full-emission simulations (including both anthropogenic and natural sources). However, the new coefficients are still based on a limited set of data. Analysis over longer periods and within various regions would be valuable to refine them.

When the fire-induced emission is integrated over the whole of Europe (from $10 \mathrm{~W}$ till $45 \mathrm{E}$ longitude and from $35 \mathrm{~N}$ till $70 \mathrm{~N}$ latitude) using the emission coefficients derived in the present study, the mean European daily $\mathrm{PM}_{2.5}$ emission from fires is $\sim 7.5 \mathrm{kton} \mathrm{day}^{-1}$ on the average in 2006-2008. This number can be compared with $\sim 9 \mathrm{kton} \mathrm{day}^{-1}$ of anthropogenic $\mathrm{PM}_{2.5}$ emission reported by European Monitoring and Evaluation Programme EMEP (Vestreng et al., 2006). According to these values, the total European fire-originated $\mathrm{PM}_{2.5}$ emission during these 3

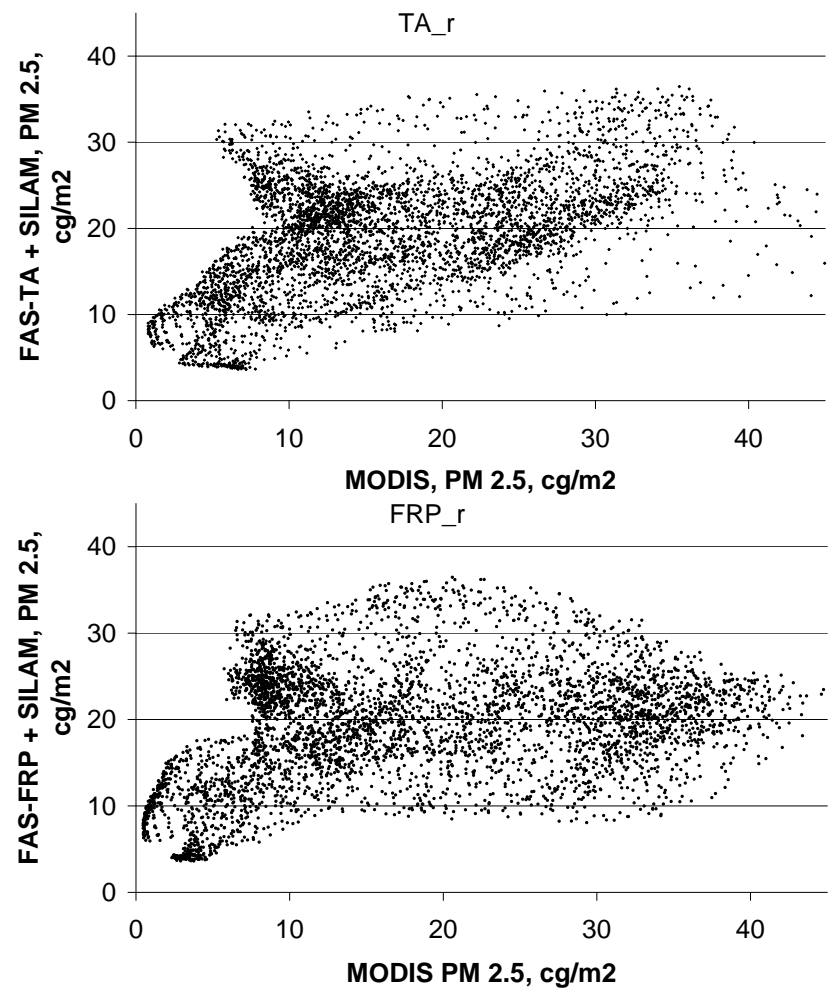

Fig. 7. Scatter-plots for FAS-TA (a) and FAS-FRP (b), using the SILAM model, compared to MODIS AOT observations (converted to $\mathrm{PM}_{2.5}$ column load) for 3.5.2006. Only fire-dominated area is included (4557 grid cells). Mean MODIS $19 \mathrm{cg} \mathrm{PM}_{2.5} \mathrm{~m}^{-2}$, mean FAS-TA $18 \mathrm{cg} \mathrm{PM} 2.5 \mathrm{~m}^{-3}$, mean FAS-FRP $18 \mathrm{cg} \mathrm{PM}_{2.5} \mathrm{~m}^{-3}$; correlation coefficients $\mathrm{RTA}=0.5, \mathrm{RFRP}=0.3$.

years is nearly the same as that of the primary anthropogenic $\mathrm{PM}_{2.5}$ emission. Clearly, both anthropogenic and fire emission estimates are substantially uncertain (Vestreng et al., 2006) and the fire emission varies from year to year (e.g. Van der Werf et al., 2006). However, one can still conclude that in Europe the fire contribution to $\mathrm{PM}_{2.5}$ were comparable with the anthropogenic contribution during recent years.

Other sources for comparison are the existing fire inventories performed using independent approaches, such as Global Fire Emission Database v.2 (GFEDv2, Giglio et al., 2006) or RETRO archive (Schultz et al., 2008). However, the comparison with both GFEDv2 and RETRO can only be made qualitatively, as these inventories only cover the period before 2006. Average fire-related emission of $\mathrm{PM}_{2.5}$ in Europe (same domain as above) for 1997-2005, according to GFEDv2, was $\sim 1 \mathrm{kton} \mathrm{day}^{-1}$. It is substantially lower than in this study but a series of record-strong fire events in spring 2006 (Russian fires), in summer 2007 (southern European and Greek fires) and August 2008 (south-eastern fires) could largely be responsible for the differences. Apart from this, according to Giglio et al. (2006), the GFEDv2 data should be considered as lower-limit estimates. The RETRO analysis 


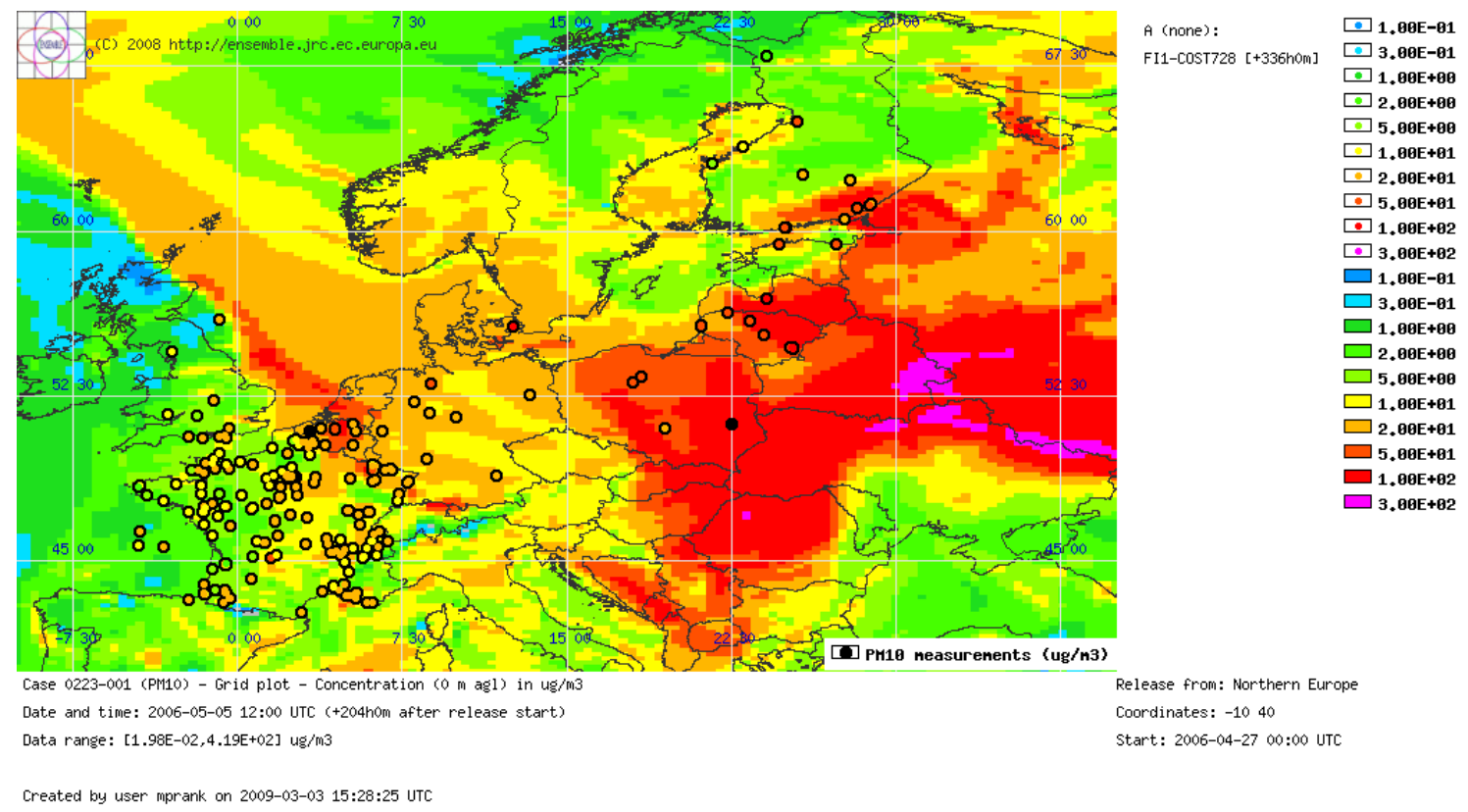

Fig. 8. Example of comparison of the model predictions (coloured plume) with in-situ AIRBASE observations (coloured circles) for PM 10 for 5 May 2006. The unit of the legend is $\mu \mathrm{g} / \mathrm{m}^{3}$.

stops in 2000 showing the long-term fluxes, which are more than twice as high as those of GFEDv2 -2.1 kton day $^{-1}$.

As a summary for the emission factor evaluation, the current methodology shows the results between the estimates of GFEDv2 and RETRO and the original IK05 emission factors. The comparison of the atmospheric dispersion predictions and with in-situ and remote-sensing observations showed that the scores varied day by day, depending on the particular episode and region. Studies over longer periods and wider areas are therefore needed to refine the emission factors.

An evaluation of the vertical distribution of the initial plumes comprised another difficult challenge for the system. Small and moderate fires do not create a sufficient plume buoyancy to reach substantially further than the top of the boundary layer. However, for the large-scale fires this may not be the case. Freitas et al. (2007) showed that injection height can exceed 5-7 km, especially if atmospheric conditions are favourable and the fires are very strong. The authors also stressed the significant impact of the latent heat flux, which can almost double the plume elevation in some cases. However, the MODIS FRP records and the FAS applications of the present study showed that strong individual fires are rare in the European conditions and have not occurred during 2006-2008 (for the cases considered within this study, a summary is presented in Fig. 9).

To estimate the uncertainty related to the simplified injection height determination, a set of year-long sensitivity computations has been performed with a single point source arbitrarily set in Central Europe, the injection height of which varied from $100 \mathrm{~m}$ to $1500 \mathrm{~m}$. The scope of this paper does not allow detailed analysis of the results but the main outcome was as follows. The simulations using the SILAM model showed that such increase of the source height resulted in a $\sim 2.5$-fold decrease of the upper percentile (98\%) of hourly concentrations (computed with regard to different meteorological situations over a year) at a distance of $60 \mathrm{~km}$ from the source. The sensitivity decreases with growing distance from the source and decreases below $10 \%$ at a distance of $\sim 250 \mathrm{~km}$. For lower percentiles, the variation is substantially smaller already in the vicinity of the source. Therefore, the assumption does not seem to lead to excessive errors even in case of comparatively strong fires.

Analysis of performance of FAS-TA and FAS-FRP did not reveal an unequivocally better approach. As seen from examples of Figs. 3, 5 and 6, the effect of the difference between the TA/FRP emission estimates for the same region and time can be as large as a factor of 4 . These differences are to be related to the retrieval algorithms. Contrary to TA, FRP depends on the background temperature determined from eight surrounding pixels (providing that they are not overheated themselves) and the actual pixel temperature. A single hot pixel surrounded by the colder ones is therefore reported as an intensive fire with a high emission rate. On the other hand, emission from widespread small-scale fires may be underestimated due to a smaller temperature differences between the adjacent pixels. Smaller difference would also tend to lead to a lower signal-to-noise ratio and to more uncertain emission estimates. 
The TA-based assessments are vulnerable to a mirroring problem: the algorithm ignores background temperature, which is used only for the classification of the fire pixels. Consequently, the TA-method does not report any fire emissions below a certain level corresponding to commonly occurring temperatures in the region. It is also not sensitive to large fires - because the brightness temperature grows slower than linearly with the fire intensity.

In a general case, the FRP algorithm tends to report higher emissions from fewer intensive locations among the comparatively low-emitting small fires. The TA approach, to the opposite, better detects small fires, and potentially underestimates the emissions from the more intensive ones. However, in commonly occurring regional applications these differences are partly averaged during compilation of emission from hundreds of fires. As a result, the emission estimates from TA and FRP for more extensive areas are usually comparable. The SILAM-based evaluation did not conclusively favour either of these two methods. For instance, the comparison in Fig. 7 reflects the day when the TA-based computations were preferable. However, during the next day the FRP-based computations were in a better agreement with observations.

A potential way to improve the emission estimates for individual fires is to use the $11-\mu \mathrm{m}$ channel to distinguish between the open flames and smouldering. However, this channel is noisier than the 4- $\mu \mathrm{m}$ one and the characteristic correlations with the type of the fire are not high. This approach has therefore not been implemented in the current FAS version.

\section{Conclusions}

The presented Fire Assimilation System consists of two branches based on partly complementary treatments of the remote-sensing information on the wild-land fires: the Temperature Anomaly and the Fire Radiative Power. The underlying methodologies are both dependent on the 4- $\mu \mathrm{m}$ temperature of the burning pixel and their output variables can be fitted one to another for moderate and strong fires. In such cases the background temperature of non-burning pixels is much smaller than the temperature of the burning ones.

The procedure of determination of the emission factors for the FAS-FRP branch is based on the approach of Ichoku and Kaufman (2005). However, in the current work the dispersion of the fire plumes was computed more rigorously using the dispersion model SILAM. We suggest a refinement of the emission factors by Ichoku and Kaufman (2005), based on the analysis of the model predictions combined with the satellite observations of column-integrated optical density and aerosol mass. According to the present study, the new factors are lower by a factor of 2 to 3 , which is qualitatively in agreement with the analysis of Ichoku and Kaufman, who suggested that their estimates can be too high.
FRP \% for MISR fire set (US) and cases 1 and 3
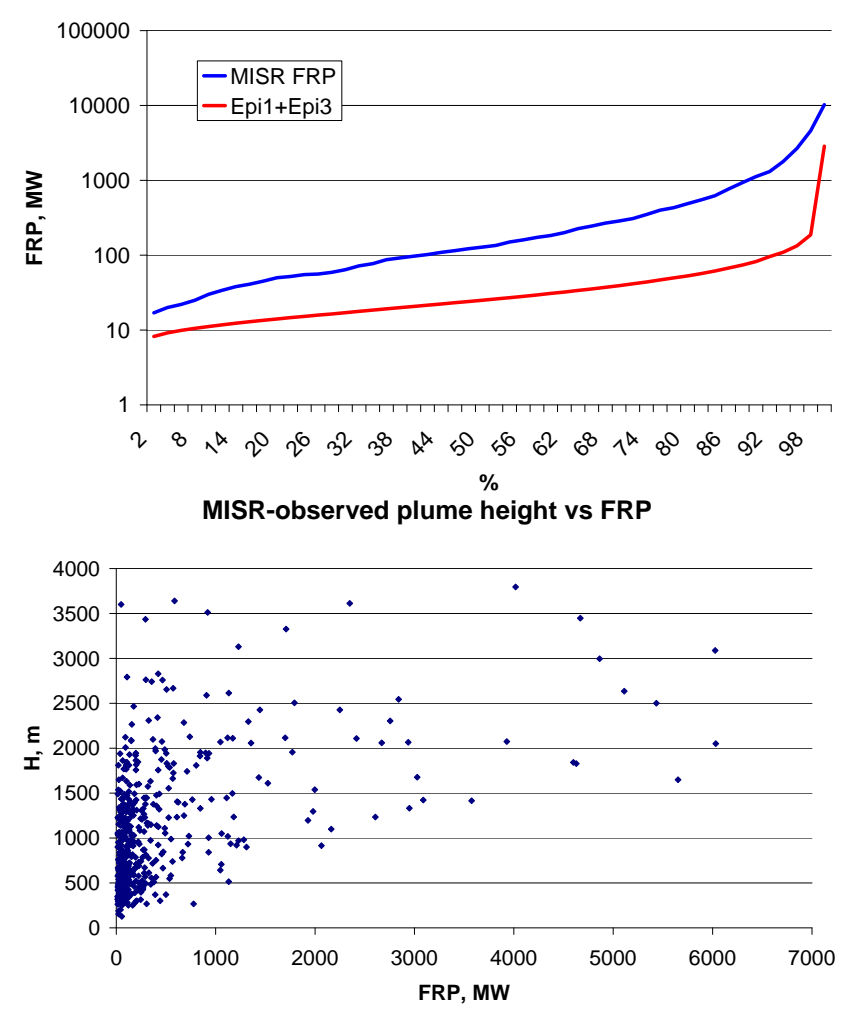

Fig. 9. Qualitative analysis of expected plume heights in Europe. (a) Percentiles for FRP for the MISR dataset (>500 fires) and episodes 1 and 3 of this study (>23000 fires); (b) observed plume heights of MISR fires.

The main inherent uncertainties of the FAS presented in this study include: (i) a simplified land use segregation, (ii) the consideration of only one type of fires (e.g., smouldering fires not treated explicitly), (iii) the possibly under-predicted diurnal variation of the fire intensity, and (iv) a simplified treatment of the vertical profile of the emission fluxes.

The described FAS has been implemented in the operational air quality forecasting suite of the Finnish Meteorological Institute, linked to the dispersion model SILAM, and used since 2006 . The related air quality predictions are routinely compared with available in-situ and remote-sensing observations and are in most cases in agreement with the observations over the areas, for which the fire-originated pollution is dominant. The differences of the peaks of columnintegrated concentrations from the observations characteristically range from $20 \%$ to $50 \%$. However, in specific cases, the difference can be substantially higher.

Acknowledgements. This study has been financed by the EUGEMS project and the Finnish Academy (IS4FIRES project). Support of the COST Action ES0602, EU-MEGAPOLI, and Estonian Ministry of Education and Research (project SF0180038s08) are kindly acknowledged. The authors wish to thank Prof. Eugene Genikhovich and Prof. Gerrit de Leeuw for their numerous 
comments and suggestions. MODIS AOD observations for the FAS evaluation were processed by the Giovanni online data system, NASA GES DISC.

Edited by: J. Brandt

\section{References}

Acker, J. G. and Leptoukh, G.: Online Analysis Enhances Use of NASA Earth Science Data, Eos, Trans. AGU, 88(2), p. 14 and p. 17, 2007.

Andreae, M. O. and Merlet, P.: Emission of trace gases and aerosols from biomass burning, Global Biogeochem. Cy., 15, 955-966, 2001.

Barbosa, P. M, Stroppiana, D., Gregoire, J. M., and Pereira, J. M. C.: An assessment of vegetation fire in Africa (1981-1991): Burned areas, burned biomass, and atmospheric emissions, Global Biogeochem. Cy., 13(4), 933-950, 1999.

Beck, J. A, Alexander, M. E., Harvey, S. D., and Beaver, A. K.: Forecasting diurnal variation in fire intensity for use in wildland fire management applications. Proc. of Forth Symposium on Fire and Forest Meteorology, Am. Met. Soc., http://ams.confex.com/ ams/4FIRE/techprogram/meeting_4FIRE.htm, 2001.

Beck, J. A. and Trevitt, A. C. F.: Forecasting diurnal variations in meteorological parameters for predicting fire behaviour, Can. J. For. Res., 19, 791-797, 1989.

Boschetti, L., Eva, H. D., Brivio, P. A., and Gregoire, J. M.: Lessons to be learned from the comparison of three satellitederived biomass burning products, Geophys. Res. Lett., 31, L2150, doi:10.1029/2004GL021229, 2004.

Chin, M., Ginoux, P., Kinne, S., Torres, O., Holben, B. N., Duncan, B. N., Martin, R. V., Logan, J. A., Higurashi, A., and Nakajama, T.: Tropospheric aerosol optical thickness from the GOCART model and comparison with satellite and sun photometer measurements, J. Atmos. Sci., 59, 461-483, 2002.

Dozier, J.: A method for satellite identification of surface temperature fields of subpixel resolution, Remote Sens. Environ., 11, 221-229, 1981.

Duncan, B. N., Martin, R. V., Staudt, A. C., Yevich, R., and Logan, J. A.: Interannual and seasonal variability of biomass burning emissions constrained by satellite observations, J. Geophys. Res., 108(D2), 4100, doi:10.1029/2002JD002378, 2003.

Flemming, J.: Emissions for GEMS (biomass burning), HALO discussion paper, Technical report, ECMWF, URL www.ecmwf.int/research/EU_projects/HALO/pdf/ paper_HALO_GEMS_emissions.pdf, 2005.

Freitas, S. R., Longo, K. M., Chatfield, R., Latham, D., Silva Dias, M. A. F., Andreae, M. O., Prins, E., Santos, J. C., Gielow, R., and Carvalho Jr., J. A.: Including the sub-grid scale plume rise of vegetation fires in low resolution atmospheric transport models, Atmos. Chem. Phys., 7, 3385-3398, 2007, http://www.atmos-chem-phys.net/7/3385/2007/.

Galperin, M. and Sofiev, M.: Errors in the validation of models for long-range transport and critical loads stipulated by stochastic properties of pollution fields. Proc. of EMEP workshop on the Accuracy of Measurements, EMEP/CCC Rep.2/94, 162-179, 1994.

Generoso, S., Bréon, F.-M., Balkanski, Y., Boucher, O., and Schulz, M.: Improving the seasonal cycle and interannual variations of biomass burning aerosol sources, Atmos. Chem. Phys., 3, 12111222, 2003,

http://www.atmos-chem-phys.net/3/1211/2003/.

Giglio, L. and Kendall, J. D.: Application of the dozier retrieval to wildfire characterization: a sensitivity analysis, Remote Sens. Environ., 77(1), 34-49, 2001.

Giglio, L., Kendall, J. D., and Mack, R.: A multi-year active fire dataset for the tropics derived from the TRMMVIRS, Int. J. Remote Sens., 24(22), 4505-4525, 2003.

Giglio, L., van der Werf, G. R., Randerson, J. T., Collatz, G. J., and Kasibhatla, P.: Global estimation of burned area using MODIS active fire observations, Atmos. Chem. Phys., 6, 957-974, 2006, http://www.atmos-chem-phys.net/6/957/2006/.

Hoelzemann, J. J., Schultz, M. G., Brasseur, G. P., Granier, C., and Simon, M.: Global wildland fire emission model (GWEM): Evaluating the use of global area burnt satellite data, J. Geophys. Res., 109(D14), D10914, doi:10.1029/2003JD003666, 2004.

Ichoku, C. and Kaufman, J. Y: A Method to Derive Smoke Emission Rates From MODIS Fire Radiative Energy Measurements, IEEE T. Geosci. Remote, 43(11), 2636-2649, 2005.

Kahn, R. A, Chen, Y., Nelson, D. L., Leung, F-Y., Li, Q., Diner, D. J., Logan, J. A.: Wildfire Smoke Injection Heights - Two Perspectives from Space, Geophys. Res. Lett., 35, L04809, doi:10.1029/2007GL032165, 2008.

Kaufman, Y. J., Justice, C. O., Flynn, L. P., Kendall, J. D., Prins, E. M., Giglio, L., Ward, D. E., Menzel, W. P., and Setzer, A. W.: Potential global fire monitoring from EOS-MODIS, J. Geophys. Res., 103, 32215-32238, 1998.

Kelh, V., Rauste, Y., Häme, T., Sephton, T., Buongiorno, A., Frauenberger, O., Soini, K., Venäläinen, A., San Miguel-Ayanz, J., and Vainio, T.: Combining AVHRR and ATSR satellite sensor data for operational boreal forest fire detection, Int. J. Remote Sens., 24(8), 1691-1708, 2003.

Keramitsoglou, I., Kiranoudis, C. T., and Sifakis, N.: A multidisciplinary decision support system for forest fire crisis management, Environ. Manage., 33, 212-225, 2004.

Labonne, M., Bre'on, F. M., and Chevallier, F.: Injection height of biomass burning aerosols as seen from a spaceborne lidar, Geophys. Res. Lett., 34, L11806, doi:10.1029/2007GL029311, 2007.

Matson, M. and Dozier, J.: Identification of subresolution high temperature sources using a thermal IR sensor, Photogramm. Eng. Rem. S., 47, 1311-1318, 1981.

Mazzoni, D., Logan, J. A., Diner, D., Kahn, R., Tong, L., and Li, Q.: A data-mining approach to associating MISR smoke plume heights with MODIS fire measurements, Remote Sens. Environ., 107, 138-148, 2007.

Nikmo, J., Tuovinen, J. P., Kukkonen, J., and Valkama, I.: A hybrid plume model for local-scale atmospheric dispersion, Atmos. Environ., 33, 4389-4399, 1999.

Prins, E., Schmetz, J., Flynn, L., Hillger, D., and Feltz, J.: Overview of current and future diurnal active fire monitoring using a suite of international geostationary satellites, edited by: Ahern, F. J., Goldammer, J. G., and Justice, C. O., in: Global and Regional Wildfire Monitoring: Current Status and Future Plans, 145-170, SPB Acad., The Hague, The Netherlands, 2001.

Reid, J. S., Prins, E. M., Westphal, D. L., Schmidt, C. C., Richardson, K. A., Christopher, S. A., Eck, T. F., Reid, E. A., Curtis, C. A., Hoffman, J. P.: Real-time monitoring of South American smoke particle emissions and transport using a coupled remote 
sensing/box-model approach, Geophys. Res. Lett., 31, L06107, doi:10.1029/2003GL018845, 2004.

Saarikoski, S., Sillanpää, M., Sofiev, M., Timonen, H., Saarnio, K., Teinilä, K., Karppinen, A., Kukkonen, J., and Hillamo, R.: Chemical composition of aerosols during a major biomass burning episode over northern Europe in spring 2006: experimental and modelling assessments, Atmos. Environ., 41, 3577-3589, 2007.

Scholes, M. and Andreae, M. O.: Biogenic and pyrogenic emissions from Africa and their impact on the global atmosphere, Ambio, 29, 23-29, 2000.

Schultz, M. G.: On the use of ATSR fire count data to estimate the seasonal and interannual variability of vegetation fire emissions, Atmos. Chem. Phys., 2, 387-395, 2002, http://www.atmos-chem-phys.net/2/387/2002/.

Schultz, M. G., Heil, A., Hoelzemann, J. J., Spessa, A., Thonicke, K., Goldammer, J., Held, A. C., and Pereira, J. M. C.: Global Emissions from Wildland Fires from 1960 to 2000, Global Biogeochem. Cy., 22, GB2002, doi:10.1029/2007GB003031, 2008.

Simon, M., Plummer, S., Fierens, F., Hoelzemann, J. J., and Ariano, O.: Burnt area detection at global scale using ATSR-2: The GLOBSCAR products and their qualification, J. Geophys. Res. A., 109, D14S02, doi:10.1029/2003JD003622, 2004.

Sofiev, M., Galperin, M., and Genikhovich, E.: Construction and evaluation of Eulerian dynamic core for the air quality and emergency modeling system SILAM. NATO Science for piece and security Serties C: Environmental Security. Air pollution modelling and its application, XIX, edited by: Borrego, C. and Miranda, A. I., Springer, 699-701, 2008.

Sofiev, M., Siljamo, P., Ranta, H., Linkosalo, T., Jaeger, S., Jaeger, C., Rassmussen, A., Severova, E., Oksanen, Karppinen, A., and Kukkonen, J.: From Russia to Iceland: an evaluation of a largescale pollen and chemical air pollution episode during April and May, 2006, Aerobiological Monographs, Vol. 1, in press, $2009 \mathrm{~b}$.

Sofiev, M., Siljamo, P., Valkama, I., Ilvonen, M., and Kukkonen, J.: A dispersion modelling system SILAM and its evaluation against ETEX data, Atmos. Environ., 40, 674-685, doi:10.1016/j.atmosenv.2005.09.069, 2006.

Soja, A. J., Cofer, W. R., Shugart, H. H., Sukhinin, A. I., Stackhouse Jr., P. W., McRae, D. J., and Conard, S. G.: Estimating fire emissions and disparities in boreal Siberia (1998-2002), J. Geophys. Res., 109, D14S06, doi:10.1029/2004JD004570, 2004
Tansey, K., Gregoire, J. M., Stroppiana, D., Sousa, A., Silva, J., Gereira, J. M. C., Boschetti, L., Maggi, M., Brivio, P. A., Fraser, R., Flasse, S., Ershov, D., Binaghi, E., Graetz, D., and Peduzzi, P.: Vegetation burning in the year 2000: Global burned area estimates from SPOT VEGETATION data, J. Geophys. Res. A., 109(D14), D14S03, doi:10.1029/2003JD003595, 2004.

Tanskanen, H. and Venäläinen, A.: The relationship between fire activity and fire weather indices at different stages of the growing season in Finland, Boreal Environ. Res., 13, ISN 1239-6095 (print), ISN 1797-2469 (online), 2008.

Trentmann, J., Luderer, G., Winterrath, T., Fromm, M. D., Servranckx, R., Textor, C., Herzog, M., Graf, H.-F., and Andreae, M. O.: Modeling of biomass smoke injection into the lower stratosphere by a large forest fire (Part I): reference simulation, Atmos. Chem. Phys., 6, 5247-5260, 2006, http://www.atmos-chem-phys.net/6/5247/2006/.

van der Werf, G., Randerson, J. T., Collatz, G. J., Giglio, L., Kasibhatla, P. S., Arellano, A. F., Olsen, S. C., and Kasischke, E. S.: Continental-scale partitioning of fire emissions during the 1997 to 2001 El Niño/La Niña period, Science, 303, 73-76, 2004.

van der Werf, G. R., Randerson, J. T., Giglio, L., Collatz, G. J., Kasibhatla, P. S., and Arellano Jr., A. F.: Interannual variability in global biomass burning emissions from 1997 to 2004, Atmos Chem. Phys., 6, 3423-3441, 2006, http://www.atmos-chem-phys.net/6/3423/2006/.

Vestreng, V., Rigler, E., Adams, M., Kindbom, K., Pacyna, J. M., Denier van der Gon, H., Reis, S., and Travnikov, O.: Inventory review 2006, Emission data reported to LRTAP and NEC Directive, Stage 1, 2 and 3 review and Evaluation of Inventories of HM and POPs, EMEP/MSC-W Technical Report 1/2006 ISSN 1504-6179, http://www.emep.int, 2006.

Wotawa, G., Novelli, P., Trainer, M., and Granier, C.: Inter-Annual Variability of Summertime CO Concentrations in the Northern Hemisphere Explained by Boreal Forest Fires in North America and Russia, Geophys. Res. Lett., 28(24), 4575-4578, 2001.

Zilitinkevich, S. S., Hunt, J. C. R., Esau, I. N., Grachev, A. A., Lalas, D. P., Akylas, E., Tombrou, M., Fairall, C. W., Fernando, H. J. S., Baklanov, A. A., and Joffre, S. M.: The influence of large convective eddies on the surface turbulence, Quarterly Journal of the Royal Meteorological Society, 132, 1423-1456, 2006. 